\title{
DELITOS, FALTAS Y CASTIGOS EN LA RUTA JACOBEA: SU PRESENCIA EN LA LITERATURA FRANCESA MEDIEVAL
}

\author{
Ignacio Ińarrea Las Heras \\ Universidad de La Rioja
}

\section{Resumen}

En el presente trabajo se quiere mostrar cómo la literatura francesa de la Edad Media se hace eco de la relación entre el mundo de la peregrinación jacobea y la transgresión de la ley y su castigo. Es realmente muy notable la variedad de géneros en los que aparece, así como de los aspectos legales abordados. La situación legal del peregrino, los delitos cometidos en el camino hacia Compostela y las condenas impuestas a los culpables constituyen en su conjunto un tema digno de atención y de análisis. Forman parte de una literatura en la cual no son un elemento de contenido de importancia primordial, pero en la que no dejan de estar presentes durante un período de más de tres siglos. Ciertamente, esta circunstancia no deja de ser un tanto contradictoria; pero eso es precisamente lo que la distingue y lo que justifica su interés como objeto de estudio.

Palabras Clave: literatura francesa medieval, peregrinación a Compostela, ley, delitos, castigos.

\section{CRIMES, FAULTS AND PUNISHMENTS IN THE JACOBEAN ROUTE: ITS PRESENCE IN MEDIEVAL FRENCH LITERATURE}

\section{Abstract}

In this research we explain how the French literature written in the Middle Ages uses the relationship between the Jacobean pilgrimage and the transgression of the law and its punishment. The legal aspects addressed as well as the different genres in which this topic appears is highly remarkable. The pilgrim's legal status, the crimes committed on the way to Compostela and the sentences imposed on the perpetrators constitute a field worth of attention and analysis. These topics belong to a kind of literature in which they are not only of paramount importance, but also recurring in the literary works written during more than three centuries. This feature seems somewhat contradictory; however, it is precisely a distinguishing one which justifies the relevance of this study.

KEYwORDs: medieval French literature, pilgrimage to Compostela, law, crimes, punishments. 


\section{INTRODUCCIÓN}

El fenómeno de la peregrinación a Compostela empezó a alcanzar una dimensión verdaderamente internacional en la Edad Media a partir, aproximadamente, del siglo $\mathrm{XI}^{\mathrm{I}}$. Esto implicó el desarrollo de un importante movimiento de peregrinos jacobeos por gran parte de Europa. Transitaban por múltiples territorios pertenecientes a distintos reinos, los cuales a su vez tenían legislaciones muy diversas. Además, podían verse expuestos a peligros de todo tipo a lo largo de su itinerario: robos, asaltos, violencia, engaños por parte de posaderos o comerciantes, etc. ${ }^{2}$. La finalidad piadosa de su esfuerzo, junto con el hecho de que con su paso por las diferentes geografías contribuían a dinamizar el comercio y aportaban riqueza, hicieron necesario establecer leyes que les proporcionasen protección y tranquilidad: «Todas las legislaciones tendieron, sin embargo, a proteger al peregrino [...]. Nace así una especie de derecho internacional protector del peregrino, en el que con rara unanimidad coinciden todas las legislaciones, y que [...] sólo empieza a esfumarse al ir perdiendo las romerías el verdadero espíritu de religiosidad y penitencia»³.

El universo del culto jacobeo, presenta, por lo tanto, una importante dimensión legal que, por su finalidad protectora con el viajero, tiene también forzosamente una función coercitiva con quienes amenazan su seguridad. La transgresión de la ley y su persecución y castigo también transitan por los caminos hacia la tumba del apóstol. Estas circunstancias tienen su reflejo escrito en textos legales como, por ejemplo, Las Siete Partidas y el Fuero Real de Alfonso X el sabio o el Fuero General de Navarrát.

Los propósitos del presente trabajo han sido mostrar qué cabida se le dio en la literatura francesa de la Edad Media a la relación entre la peregrinación a Compostela, la comisión de delitos y la administración de justicia, determinar su complejidad y su variedad y establecer su alcance y su importancia como elemento temático en dicha producción literaria.

\section{LOS PELIGROS Y LAS LEYES}

Según señala Valérie Toureille, las fuentes documentales que se pueden manejar para llevar a cabo un estudio en profudidad sobre la cuestión específica del crimen en la Francia de la Edad Media son escasas e inconexas:

1 Vid. L. Vázquez de Parga, J.M. ${ }^{a}$ Lacarra y J. Uría Ríu, Las peregrinaciones a Santiago de Compostela. 3 vols. Madrid, Consejo Superior de Investigaciones Científicas, 1949, vol. 1, p. 47 (en adelante L. VÁzquez de Parga, J.M.a Lacarra y J. Uría Ríu, Las peregrinaciones).

2 Vid. ibidem, pp. 255 y $265-273$.

3 Ibidem, p. 255.

4 Vid. ibidem, pp. 255-276. 
L'historien aimerait disposer, pour mieux saisir tous les aspects du crime, de sources abondantes et variées. Il doit, pour la période médiévale, se contenter de sources souvent sporadiques et décousues [...] s'accommoder de bribes de documents dans lesquelles il puise sans pouvoir toujours les appareiller ${ }^{5}$.

Por otra parte, Valérie Toureille afirma igualmente que los textos medievales de naturaleza literaria tampoco conceden al crimen un lugar realmente destacado. Por lo tanto, el valor de la literatura de esta época como testimonio fiable acerca de dicho tema no es demasiado considerable:

Quant à la littérature ou à l'iconographie, il faut leur accorder un crédit limité. Toutes choses égales par ailleurs, un historien qui chercherait à comprendre la société contemporaine par la seule lecture des magazines de mode serait victime des mêmes biais. L'iconographie, peuplée de supplices de saints, n'en est que plus suspecte. L'immense fonds romanesque demeure peu intéressé par le sujet, lequel sujet ne prête pas toujours à rire au point d'alimenter à l'excès les fabliaux ${ }^{6}$.

A pesar de ello, es posible encontrar a algunos autores y varios géneros literarios que llegan a dar una visión más cercana de las prácticas delictiva y judicial en la Francia medieval y, en concreto, de su presencia en el contexto del culto jacobeo. Tenemos así el caso de Eustache Deschamps (1306-1406). Hoy se le recuerda sobre todo por su abundante producción poética, pero no se debe obviar que también estuvo estrechamente vinculado al mundo de las leyes. Estudió derecho en Orleáns y ejerció como bailli en Valois y en Senlis?.

Los conocimientos de Eustache Deschamps en materia judicial quedan reflejados en no pocas de sus producciones poéticas. En una de sus baladas (la número 167, en la edición a cargo del marqués de Queux de Saint-Hilaire y de Gaston Raynaud), hace un llamamiento a los profesionales de la justicia para que ejerzan sus funciones de castigo, mediante la condena a muerte en la horca, contra aquellos que llevaron a cabo la revuelta de los Maillotins en París, en 1382. Llama la atención en esta composición, por ejemplo, la abundante presencia de vocabulario relativo a cargos relacionados con la administración de justicia:

Or sus, or sus, baillis et seneschaulx,

Prevosts, viguiers, vicontes, lieutenans,

5 V. Toureille, Crime et châtiment au Moyen Âge: Ve-XVe siècle. París, Seuil, 2013, p. 15 (en adelante V. Toureille, Crime et châtiment).

6 Ibidem, p 16.

7 Vid. Eustache Deschamps, Euvres complètes d'Eustache Deschamps. 11 vols. Marqués de Queux de Saint-Hilaire y Gaston Raynaud (eds.). París, Firmin Didot, 1878-1903, vol. 11, pp. 13, 17 y 57 (en adelante Eustache Deschamps, Euvres complètes) y V. Toureille, Crime et châtiment, p. 218 , n. 2. 
Et procureurs! alez cerchier les maulx,

Mettez vous sus, conseilliers et sergens ${ }^{8}$.

La vinculación de la práctica delictiva con las peregrinaciones debió de ser una realidad conocida por Eustache Deschamps. Así se desprende de lo que este autor señala en un pasaje de la Fiction du Lyon. Es esta una obra de carácter alegórico y dedicada a criticar el reinado de Carlos VI de Francia. Eustache Deschamps compara a este monarca con su padre, Carlos V, modelo de buen gobernante y representado como el león Noble. En ella aparece también el personaje de Renard, que no es otro que Carlos II el Malo, rey de Navarra. Renard es enemigo de Noble y ambiciona apoderarse de su reino?. Eustache Deschamps identifica a Renard como un personaje

Qui venoit des marches d'Espagne.

Nez ne fut pas en Alemaigne,

Mais vers Pampelune en ces vaulx

Et es marches de Roncevaul $x^{10}$.

Ofrece de él un retrato nada halagador, pues lo presenta como un hipócrita y un traidor sin escrúpulos. Asimismo, y en relación con la práctica del culto jacobeo, Renard aparece como un buen conocedor del Camino de Santiago y, gracias a ello, como un consumado asesino y ladrón de peregrinos:

Bien sçavoit la voye en Galice,

Car maint pelerin avoit mort

Par poison et donné la mort,

Et maint autre en agait tué,

Sanz riens avoir restitué ${ }^{11}$.

Aunque se trata de una narración alegórica, la Fiction du Lyon se hace eco en estos versos del riesgo que corrían los viajeros piadosos hacia Compostela de ser víctimas de desaprensivos y criminales.

La Fille du Comte de Ponthieu muestra también este peligro. Se trata de un texto narrativo en prosa, escrito a comienzos del siglo XIII y de autor desconocido.

8 Eustache Deschamps, Euvres complètes, vol. 1, p. 298, vv. 1-4. Vid. ibidem, vol. 11, p. 36, n. 4 y V. Toureille, Crime et châtiment, pp. 218-219. Proponemos la siguiente traducción al castellano para esta cita: «iVamos, vamos, bailes y magistrados, / Oficiales de justicia, vegueres, vizcondes, administradores, / Y fiscales! Id a buscar a la mala gente, / Perseguidlos, consejeros y oficiales del orden».

9 Vid. Eustache Deschamps, Euvres complètes, vol. 11, pp. 159-164.

10 Ibidem, vol. 8, p. 328, vv. 2643-2646. Proponemos la siguiente traducción al castellano para esta cita: "Que venía de las marcas de España. / No estuvo en Alemania, / Sino por Pamplona, en aquellos valles / y marcas de Roncesvalles».

11 Ibidem, p. 330, vv. 2696-2700. Proponemos la siguiente traducción al castellano para esta cita: «Conocía bien el camino hacia Galicia, / Porque a muchos peregrinos había matado / Por envenenamiento, / Y a muchos otros en emboscadas, / Sin haber restituido nada». 
Cuenta en su parte inicial la peregrinación a Compostela que un joven matrimonio, formado por Thibaut y la hija del conde de Ponthieu, realizan para rogar al apóstol que les conceda un heredero. En el trayecto hacia Galicia tendrán un mal encuentro con unos salteadores de caminos, y serán víctimas de tres actividades delictivas. La primera de ellas es el asesinato en forma de tentativa. Thibaut se defenderá de los ataques de estos bandoleros y matará a tres de ellos:

Et il [unos de los bandidos] muet a lui le glave et le quide ferir parmi le cors. Et mesire Tiebaus vit le cop venir, si douta et baisa le cors, et cil fali a lui, mais, au trespaser, jeta mesire Tiebaus le main deseure le glave, si le toli au laron, et mut as trois dont cil estoit mus, et en fiert un parmi le cors, si l'ocit, et il recuevre et muet ariere, et fiert celui qui primes estoit mus a lui parmi le cors, et l'ocit ${ }^{12}$.

El segundo delito es el robo, pues tanto Thibaut como su mujer son despojados de sus ropas. A la joven le quitan también su caballo. El tercero, que es el de consecuencias más graves, es la violación de la esposa por los asaltantes:

Et elle estoit molt bele, et nepourquant si plouroit elle molt durement. L'un des larons l'esgarda et dist: «\$Segneur, j’ai mon frere perdu, si voel avoir ceste dame en restor». Li autres dist: - «Ausi ai jo men cousin germain, autan i clain jou comme vous». Et autel dist li tiers, et li quars. Et li quins leur dist: - «Segneur, en li retenir n’arons nous mie grant preu, mais menon le en ceste forest et faisons de li nos volentés, puis le remetons a voie et le lasons aler». Ensi le fisent, et le remenerent a le voie ${ }^{13}$.

Hay varios aspectos importantes que deben ser tenidos en cuenta aquí. Los bandidos no sufren castigo alguno por haber cometido el robo y la violación. No hay detención, juicio ni condena para ellos. Quedan, pues, impunes. Aunque sí pueden interpretarse como un castigo anticipado las tres muertes de los bandoleros a manos de Thibaut. De todas maneras, este es un caso muy claro de legítima defensa por su parte. A este respecto, el jurista Philippe de Beaumanoir (1250-1296), bailli

12 Anónimo, La hija del conde de Ponthieu / La fille du Comte de Ponthieu. Esperanza Cobos Castro (ed.). Barcelona, Bosch, 1988, p. 100 (en adelante Anónimo, La hija del conde de Ponthieu). Traducción al castellano de esta cita, a cargo de Esperanza Cobos Castro: «Y dirigiendo hacia él la espada pensó atravesarle el cuerpo. Thibaut vio el golpe venir, lo esquivó, bajó el cuerpo, y aquél no le alcanzó; mas, al pasar, Thibaut echó mano a la espada, se la quitó al ladrón y se dirigió hacia los tres de entre los cuales había salido su atacante, atravesó a uno y lo mató; volvió a la carga y se dirigió hacia atrás hiriendo al primero que había ido hacia él, le atravesó el cuerpo y lo mató». Ibidem, p. 101.

13 Ibidem, p. 102. Traducción al castellano de esta cita, a cargo de Esperanza Cobos Castro: «Era muy hermosa y lloraba amargamente. Uno de los ladrones la miró y dijo: "Señores, yo he perdido a mi hermano, así que quiero tener esta dama como recompensa". Otro dijo: "Yo también he perdido a mi primo, y pido lo mismo que vos". Lo mismo dijo el tercero y el cuarto. Entonces el quinto sugirió: "No sacaremos mucho provecho reteniéndola, llevémosla a ese bosque, saciemos con ella nuestros deseos, luego pongámosla en el camino y dejémosla ir". Así lo hicieron y la volvieron a poner en el camino». Ibidem, p. 103. 
en Senlis, Clermont, Tours y en el Vermandois, señala lo siguiente en su obra Coutumes de Beauvaisis (1283):

Metre autrui a mort seur soi defendant est quant aucuns ne se donne garde que l'en le doie assaillir et l'en l'assaut par haine ou pour li rober ou a la requeste d'autrui par louier. Se cil qui en tel maniere est assaillis voit qu'il gietent à lui sans merci cous qui portent peril de mort, et est si apressés qu'il ne se puet metre a garant, il li loit a soi defendre; et s'il, en soi defendant, en met aucun a mort, on ne l'en doit riens demander, car il le fet pour la mort eschiver. Et s'il est apelés en jugement seur cele occision, il puet bien venir avant et atendre droit, mes qu'il puist bien estre prouvé qu'il le fist seur soi defendant, si comme il est dit dessus ${ }^{14}$.

Como se ha podido ver, la violación es planteada por algunos de los salteadores como una especie de compensación por el perjuicio personal que para ellos ha supuesto la muerte de sus compañeros, con los que tenían algún lazo de parentesco. Violar a la mujer de Thibaut es para ellos una forma legitima de resarcirse del daño moral sufrido. Es realmente curioso ver aquí el ejercicio de una forma extraña de justicia, planteada desde el punto de vista de los delincuentes. Es una justicia a la inversa. Lo que Philippe de Beaumanoir define como una acción por la cual no se deben pedir cuentas a su autor (en este caso Thibaut), pues la ha realizado por le mort esquiver, supone para estos criminales un agravio. Y, por lo tanto, cometer el delito de violación es, a su modo de ver, una adecuada reparación.

Por último, hay que señalar que La Fille du Comte de Ponthieu plantea una situación que cabría considerar como inaudita en el panorama criminal y judicial de la Edad Media, aunque bien es verdad que se trata de un episodio ficticio. Después de haber sido violada por los salteadores de caminos, la joven intenta matar con una espada a su propio marido, que había sido atado por los bandidos. La esposa fracasa en su intento, aunque llega a herirle, y, extrañamente, dice que lamenta no haber conseguido su propósito.

Et mesire Tiebaus le vit et dist li: «Dame, pour Diu, desliés me, car ces ronses me grievent molt». La dame vit une espee gesir ki fu a un des larons qui ocis fu, si le prist et vint vers monsegneur Tiebaut, si dist: «Sire, je vous deliverai». Elle le cuida ferir parmi le cors, et il vit le cop venir, si le duta, et si durement tresali que les mains et li dos li furent deseure. Et elle le fiert si qu'elle le bleça es bras et copa les coroies. Et il senti les mains laskier, et saca a lui, et rompi les loiens, et sali sus

14 Philippe de Beaumanoir, Coutumes de Beauvaisis. 2 vols. A. Salmon (ed.). París, Picard, 1899-1900, vol. 1, p. 450 (en adelante Philippe de Beaumanoir, Coutumes de Beauvaisis). Proponemos la siguiente traducción al castellano para esta cita: «Matar a otros en defensa propia sucede cuando uno no se da cuenta de que van a matarle y le asaltan por odio, por robarle, o por encargo de alguien que ha pagado por ello. Si aquel que es asaltado de esta forma ve que se lanzan a por él sin piedad quienes le ponen en peligro de muerte y se encuentra tan acorralado que no se puede proteger, debe defenderse; y si al defenderse da muerte a alguien, no se le puede acusar de nada, ya que lo hace para evitar la muerte. Y si es llamado a juicio por tal muerte, él puede presentarse y esperar justicia, siempre que esté probado que él lo hizo para defenderse, como se ha dicho antes». 
en piés, et dist: «Dame, se Diu plaist, vous ne me ocirés huimans!» Et elle li dist: «Certes, sire, ce poise moi». Il li toli l'espee et li mist le main sur l'espaule et l'en remena le voie qu'il estoient venu' ${ }^{15}$.

Tras el regreso, Thibaut cuenta al padre de su esposa el incidente de los bandidos y la sorprendente reacción de ella. Preguntada sobre esto por su padre, se reafirma en su pesar por no haber podido matar a Thibaut:

«Dont fu ce ma fille cui ensi avint? - Sire», fait il, «voire. -Tiebaut» fait il, «bien en estes vengiés qui ramenee le m'avés». A le grant ire qu'il avoit il apiela la dame et li demanda se voirs estoit que messire Tiebaus avoit dit, et elle demanda «Coi? -Q'ensi le vausistes occire. -Sire», fait elle, «oïl. -Pour que le vausistes vous faire? -Sire», fait elle, "pour çou q'encore me poise ke jo ne le fiss»"16.

Hacia el final del relato, la hija del conde de Ponthieu, convertida en esposa del sultán de Almería, se reencontrará con su padre, su esposo y su hermano. Será entonces cuando ella revelará el motivo por el cual intentó dar muerte a Thibaut:

-«A!», fait la dame, «[...] bien sai por quoi ele le vaut ocirre. -Dame, por quoi? -Por le grant honte qu'il avoit veu que ele avoit soufferte et rechut devant lui». -Et quant mesires Tiebaus l'oï, si commencha a plorer molt tenrement et dist: «Elas!, ques coupes i avoit ele? Dame», fait il, «si me voelle Diex delivrer de la prison u je sui, ja por ce pieur sanllant ne l'en eusse fait. -Sire», fait ele, «che ne cuidoit ele mie adont ${ }^{17}$.

15 Anónimo, La hija del conde de Ponthieu, p. 104. Traducción al castellano de esta cita, a cargo de Esperanza Cobos Castro: «Thibaut la vio y le dijo: "Señora, por Dios, desliadme que estos espinos me hacen mucho daño". La dama vio en el suelo la espada de uno de los ladrones que habían muerto, la cogió y se aproximó hacia Thibaut diciendo: "Yo os liberaré, señor". Pensó atravesarle el cuerpo, pero él vio venir el golpe, lo esquivó y se estremeció tan violentamente que las manos y los dedos se le quedaron libres. La dama le hirió en un brazo y cortó las correas. Él sintió que las manos se le soltaban, tiró, rompió las ligaduras, dio un salto, se puso en pie y gritó: “¡Dama, por Dios, ya no me mataréis!" A lo que ella respondió: "Cierto, señor, y mucho me pesa”. Thibaut le quitó la espada, le puso una mano sobre el hombro y la condujo de nuevo hasta el camino por donde habían venido". Ibidem, p. 105.

16 Ibidem, p. 110. Traducción al castellano de esta cita, a cargo de Esperanza Cobos Castro: “Luego, ¿fue mi hija la que actuó de ese modo?” "Así es.” “Bien os habéis vengado al traérmela, Thibaut!" Con todo el gran furor que sentía, llamó a la dama y le preguntó si era verdad lo que Thibait le había relatado, y ella preguntó: "Qué?" "Que quisísteis matarle." "Sí, señor.” “¿Por qué quisísteis hacerlo?". "Aún me pesa no haberlo hecho, señor."”. Ibidem, p. 111.

17 Ibidem, p. 134. Traducción al castellano de esta cita, a cargo de Esperanza Cobos Castro: "“Ah! - dijo la dama-, [...] sé por qué quiso matarlo.” “Por qué, señora?”. "Por la gran vergüenza que ella había sufrido y recibido delante de él”. Y cuando Thibaut la oyó comenzó a llorar tiernamente y dijo: “¡Ay!, pero ¿qué culpa tenía ella? Así quiera Dios librarme de la prisión en que me encuentro, señora: Nunca hubiera puesto peor cara por ello". "Eso no era lo que ella pensaba entonces", respondió la dama». Ibidem, p. 135. 
La reacción que, en forma de pregunta, tiene Thibaut ante la explicación de su esposa es una manera de hacerle justicia en dos sentidos. Primeramente, confirma que la joven es libre de toda responsabilidad en la violación sufrida. Habría aquí una cierta forma de coherencia con el tratamiento que la justicia medieval francesa hacía de este delito, considerado como de mucha gravedad: «Les coutumiers isolent les crimes majeurs pour lesquels il ne saurait y avoir attermoiements de justice: ils se comptent au moins quatre, le meurtre, le vol, l'incendie, le rapt ou le viol» ${ }^{18}$. Podía castigarse con penas severas como la horca, la mutilación o el destierro ${ }^{19}$. En segundo lugar, se deja claro que la sorprendente tentativa de homicidio por parte de la mujer de Thibaut tenía una justificación moral. De una manera extrañamente moderna, podría interpretarse su reacción como un caso de eutanasia moral. Darle muerte hubiera significado liberarlo para siempre de un gran dolor y una enorme humillación. Suscribimos aquí la interpretación propuesta al respecto por Rita Lejeune: «Elle se décide à expliquer la raison de son acte, une raison faite de plusieurs sentiments mais où la peur de voir souffrir son mari apparaît pour la plus grande part ${ }^{20}$. Por ello, y a pesar de lo extraño de la situación, la joven no merecía ser castigada. Se cometió con ella una injusticia, explicable por el hecho de que ni después del asalto ni al regreso de la peregrinación aclara la causa de su proceder.

El Dit des.III. pommes de Jean de Saint-Quentin (siglo xIv) es otro ejemplo de texto de ficción que aborda la vulnerabilidad del peregrino jacobeo. Un joven que va a Compostela, para cumplir por delegación el voto hecho por su padre, es asesinado en el albergue en el que pernocta. Los autores del crimen son la mujer del posadero y su amante, que quieren quedarse con el dinero del muchacho:

«Amis, dit la mauvesse, bien puissiéz vous venir

Comme l'omme du monde que miex ains et desir.

Un enfant est ceans qu'il vous couvient murtrir».

- «Dame, dit le murtrier, je ferai vo plaissir»

Li enfez fu murtris a duel et a dolour ${ }^{21}$.

18 N. Gonthier Le châtiment du crime au Moyen Âge: XIIe-XVIe siècles. Rennes, Presses Universitaires de Rennes, 1998, p. 198 (en adelante, N. GonTHIER Le châtiment du crime).

19 Vid. ibidem, p 163.

20 R. Lejeune, «Une nouvelle française du XIII ${ }^{\mathrm{e}}$ siècle et un film japonais de 1951», en Studi in onore di Italo Siciliano. 2 vols. Florencia, Leo S. Olschki, 1966, vol. 2, p. 648.

21 Jehan de Saint-Quentin, Dits en quatrains d'alexandrins monorimes de Jehan de SaintQuentin. Birger Munk Olsen (ed.). París, Société des Anciens Textes Français, 1978, pp. 31-32, vv. 157161 (en adelante Jehan de Saint-Quentin, Dits). Proponemos la siguiente traducción al castellano para esta cita: “Amigo", dijo la malvada, "bien podéis venir / Como el hombre al que más amo y deseo en el mundo. / Hay aquí un muchacho al que debéis matar". / "Señora", dijo el asesino, "os daré gusto" / El joven fue asesinado de forma dolorosa». 
El asesinato no es muy verosímil, pues no parece responder a la realidad de la peregrinación jacobea medieval ${ }^{22}$. La muerte del joven se explica, dentro de la ficción, para justificar la intervención milagrosa que le hará resucitar. En cambio, los robos cometidos en las posadas de la ruta jacobea sí que eran más frecuentes. En esto Le Dit des.III. pommes sí refleja con fidelidad la realidad histórica: «Si el robo en despoblado no era frecuente y estaba tan severamente castigado, más difícil de evitar y aun de probar era el robo a los peregrinos en posadas y hospederías, en que el posadero mismo podía ser autor o al menos encubridor ${ }^{23}$.

Un género literario medieval que también debe ser tenido en cuenta aquí por su obligada cercanía a la realidad histórica que recoge es la crónica. La transgresión de la ley, la violencia, la criminalidad tienen en ella un hueco: «Les chroniques se multiplient à l'extrême fin du Moyen Âge. CEuvres de témoins privilégiés, anonymes ou connus, elles jettent un regard sur la société dans laquelle ils vivent et nous fournissent, çà et là, des informations parfois anecdotiques, souvent remarquables, sur la matière criminelle» ${ }^{24}$. En concreto, las Chroniques de Jean Froissart (1337-1404?) no carecen de alusiones a la peregrinación jacobea. Entre ellas, hay algunos comentarios acerca de la situación legal de protección de la cual gozaban quienes iban a Galicia a rendir culto a la tumba del apóstol. En su relato de la batalla de Auberoche (1345), acontecida entre tropas francesas e inglesas en el marco de la Guerra de los Cien Años, cuenta Jean Froissart cómo llegó un grupo de peregrinos de Flandes, procedentes de Santiago, al campamento francés y fueron objeto, por su propia condición de caminantes piadosos, de un trato hospitalario y amigable. Más tarde, pasaron por territorio que se encontraba bajo dominio inglés y también se les trató con respeto por el mismo motivo:

En ce propre jour [...], passèrent parmi l'oost pèlerins de Flandre, liquel retournoient de Saint-Jaque en Galise. On ne lor fist nul mal, mais toute courtoisie pour l'amour dou pèlerinage [...]. Quant il orent beu et mengié, il passèrent oultre et vinrent ce soir jésir à Pellagrue [Pellegrue] qui estoit englesce. On ne lor demandoit partout riens pour tant que il estoient pèlerin de Saint-Jaquème ${ }^{25}$.

22 L. Vázquez de Parga, J.M. ${ }^{a}$ Lacarra y J. Uría Ríu no mencionan la muerte del peregrino a manos de maleantes como un peligro frecuente en las rutas jacobeas. En todo caso, vid. VÁzQUEZ de Parga, J.M.a Lacarra y J. Uría Ríu, Las peregrinaciones, vol. 1, p. 315.

23 Ibidem, vol. 1, p. 271.

24 V. Toureille, Crime et châtiment, p. 29.

25 Jean Froissart, Euvres de Froissart. Chroniques. 25 vols. Barón Kervyn de Lettenhove (ed.). Bruselas, Devaux, 1867-1877, vol. 4, p. 268 (en adelante Jean Froissart, Euvres de Froissart). Proponemos la siguiente traducción al castellano para esta cita: «Ese mismo día [...] pasaron entre las tropas unos peregrinos de Flandes, que volvían de Santiago en Galicia. No se les hizo ningún dańo, sino que se les trató cortésmente por respeto a la peregrinación. Cuando hubieron comido y bebido, continuaron su camino y fueron a pernoctar a Pellegrue, que estaba en manos inglesas. No se les preguntó nada en ninguna parte, por ser peregrinos de Santiago». 
Asimismo, Jean Froissart cuenta cómo el caballero Espang de Lyon, su acompañante durante su viaje a la corte de Gastón Fébus, conde de Foix, le habla del asedio del castillo de Trigalet (Tuzaguet) por Garsis du Chastel, militar al servicio del conde de Anjou. La situación de guerra hacía imposible transitar por el territorio en que se encontraba dicho castillo. Los peregrinos eran en esto una excepción: «Ne nuls ne povoit passer, ne chevauchier parmy ce pays, se il n'estoit pellerin alant à Saint-Jacques, com fort qu'il fuist de gens, qu'il ne fuist prins mort ou ranchonné» ${ }^{26}$.

Es preciso señalar que en la Francia medieval también aparecieron textos legales en los que se recogía la situación especial de la que gozaban los peregrinos en el transcurso de su aventura. Un ejemplo claro son las mencionadas Coutumes de Beauvaisis de Philippe de Beaumanoir. Al final del capítulo 25 de esta obra, su autor establece que no se debe causar trastorno alguno a dichos viajeros:

Entre les autres choses que nous avons dites des aisemens communs que chascuns doit avoir es chemins pour aler et pour venir pesiblement, tuit li seigneur doivent mout prendre garde que li pelerin ne soient pris ne destourbé pour petite achoison, car c'est mal de destourber ceus qui sont en voie de bien fere; et se aucuns les areste ou destourbe a tort ou pour petite achoison, li souverains les doit fere delivrer et rendre leur damages, et aussi de tous autres estranges qui vont par les chemins ${ }^{27}$.

Como se puede comprobar al final de la cita, es de justicia que a todo peregrino que haya sido objeto de una detención equivocada se le ofrezca la debida compensación por los inconvenientes sufridos.

Estas últimas consideraciones nos llevan necesariamente a revisar otra parte de la obra de Philippe de Baumanoir, concretamente el capítulo 69. En él se cuenta un caso de especial gravedad, un error judicial. Un peregrino (no se precisa cuál era su destino) fue detenido indebidamente cuando se encontraba en una taberna, junto con varias personas a las que había conocido causalmente allí. Los integrantes de este grupo habían sido acusados de robo y asesinato. El peregrino fue considerado por las autoridades como un miembro más del mismo. Todos fueron condenados a muerte, incluido el peregrino, que fue tachado de farsante. Aquí ya no hay lugar a satisfacción o reparación alguna para el viajero. Según Philippe de Beaumanoir, no

26 Ibidem, vol. 11, p. 45. Proponemos la siguiente traducción al castellano para esta cita: «Nadie podía pasar ni cabalgar por este territorio sin ser muerto o apresado, a no ser que fuera peregrino con destino a Santiago».

27 Philippe de Beaumanoir, Coutumes de Beauvaisis, vol. 1, p. 382. Proponemos la siguiente traducción al castellano para esta cita: «Entre las cosas que hemos dicho sobre las facilidades comunes que cada uno debe tener en los caminos para ir y venir pacíficamente, todos los señores deben tener gran cuidado con que el peregrino no sea detenido ni molestado por causas sin importancia; porque está mal importunar a los que están en el camino de bien obrar; y si alguno los detiene, les causa molestias por error o por motivos poco importantes, el señor debe hacer que los liberen y que les reparen los daños causados; y también [se obrará así] con todos los forasteros que transiten por los caminos». 
queda más que aconsejar que la justicia mejore su forma de actuar y también que los peregrinos escarmienten en cabeza ajena, evitando las malas o dudosas compañías:

Et assés tost après furent pendu et trainé pour pluseurs mesfés, et li pelerins avec, car l'en ne le vout pas croire qu'il ne fust leur compains, et encore li pires pour ce qu'il fesoit le pelerin: et ainsi fu mis a mort cil qui coupes n'i avoit par soi embatre en mauvese compaignie. Et en ceste aventure puet on prendre deus essamples: l'une que la justice qui prent plenté de gens pour soupeçon de mesfet sache le mesfet de chascun avant qu'il soit justiciés; l'autre que l'en se gart d'entrer en mauvese compaignie, tout soit ce que l'en ne pense se bien non, pour les perius qui en pueent avenir ${ }^{28}$.

Así pues, a pesar de la protección legal que se proporcionaba a los peregrinos, estos podían ser víctimas no solamente de abusos por parte de desaprensivos o delincuentes, sino también de errores cometidos por quienes deberían garantizar su protección durante el viaje. Se comprueba, además, que la figura del falso peregrino estaba entonces lo bastante extendida en Francia como para generar desconfianza y ser incluso objeto de persecución y castigo. Los famosos Coquillards, delicuentes miembros de una auténtica organización criminal del siglo xv, ejercían también como aparentes peregrinos para poder cometer sus delitos ${ }^{29}$.

En cualquier caso, la detención y encarcelamiento de un peregrino por error aparece recogida también en la literatura francesa medieval. Tenemos dos pruebas de ello, aunque de muy escasa extensión, en la recopilación de ejemplos de carácter moral conocida con el título de Ci nous dit (primer tercio del siglo xIv). En los ejemplos 673 y 674 se habla de peregrinos de Compostela encarcelados y liberados por la intervención del apóstol Santiago. Se diría que, de esta forma, la justicia divina actúa en la tierra para corregir los errores de la justicia humana. $Y$ es que en los dos relatos se muestra a los peregrinos en prisión a tort. En el primero se señala esta circunstancia desde el principio:

Ci nous dit conment uns pelerins estoit en prison a tort, qui alloit ou veage de saint Jaque. Saint Jaque s'apparut a lui en la prison et li dist qu'il montast au derain estage

28 Ibidem, vol. 2, pp. 490-491. Proponemos la siguiente traducción al castellano para esta cita: «E inmediatamente después fueron ahorcados y arrastrados por varios delitos, y el peregrino también, ya que no quisieron creer que no fuera su compañero [de los otros detenidos]; y aún fue considerado el peor, porque se hacía pasar por peregrino: y así fue muerto quien no tenía culpa, por estar en mala compañía. Y de esta aventura se pueden sacar dos enseñanzas: una, que la justicia que detiene a muchas personas como sospechosas de delitos debe conocer el delito de cada una antes de que sean ajusticiadas; otra, que hay que guardarse de estar en mala compañía, aunque uno no piense mal, por los riesgos que pueden correrse».

29 Vid. L. Vázquez de Parga, J.M. a Lacarra y J. Uría Ríu, Las peregrinaciones, vol. 1, pp. 115-116 y 122-124 y V. Toureille, Crime et châtiment, p. 135. 
de la tour. Et en l'eure qu'ill i fu montez, la tour se plia aussi comme une verge et le mist jus a terre tout bellement. Et ainsi fu hors de prison ${ }^{30}$.

En el segundo ejemplo no se habla de encarcelamiento equivocado: «Ci nous dit conment uns pelerins de saint Jaque estoit en prison. Et saint Jaques li derompi sez chaiennes et li dist qu'il emportast un troncon a son eglyse en Calice. Et de la vertu de ceste chaienne, larrons et toutes bestes sauvages s'enfouioient devant li. Et ainssi fu delivrez ${ }^{31}$. Pero si se revisa la relación numerada de todos los capítulos, se puede comprobar que el 674 aparece identificado y resumido como sigue: «Cy dit d'un autre pelerin qui fu mis a tort en prison et saint Jaques lui rompi ses chaines et lui dist qu'il en portast un tronçon en son eglise» ${ }^{32}$. Por otra parte, no deja de ser interesante a alusión los ladrones y a los animales salvajes como peligros existentes en el camino.

\section{VENGANZAS, CONDENAS Y PENITENCIAS}

Jean Froissart narra en sus Chroniques la recuperación por parte del caballero Gauthier de Mauny de los restos mortales de su padre, Jean de Mauny. Esto ocurre después de la toma de La Réole por parte de Enrique de Lancaster, conde de Derby, en 1345. Jean de Mauny, conocido también como le Borgne de Mauny, fue asesinado en esta localidad al regreso de su peregrinación a Santiago de Compostela $^{33}$. El autor de la fechoría fue Jean de Lévis, señor de Mirepoix. Lo hizo para vengarse de Jean de Mauny, que había matado involuntariamente, durante un torneo, a su hermano ${ }^{34}$. Aunque Jean de Mauny y la familia de Mirepoix quedaron en paz tras el incidente, la venganza se realizó de todas maneras: «Nientmains les linages de celuy ochirent le chevalier, et fu là ensevelis. Depuis en prist messire Gautier sy grande venganche qu'il destruisy tout cheulx de Mirepois, la guerre durant

30 Anónimo, Ci nous dit. Recueil d'exemples moraux. 2 vols. Gérard Bangez (ed.). París, Société des Anciens Textes Français, 1979-1986, vol. 2, p. 186. Proponemos la siguiente traducción al castellano para esta cita: «Aquí se nos cuenta cómo un peregrino que iba a Santiago estaba en prisión por error. Santiago se le apareció en la cárcel y le dijo que subiera a lo más alto de la torre. Y cuando hubo subido, la torre se dobló como una vara y le dejó con cuidado en el suelo. Y así salió de la prisión».

31 Ibidem. Proponemos la siguiente traducción al castellano para esta cita: «Aquí se nos cuenta cómo un peregrino de Santiago estaba en prisión. Y Santiago rompió sus cadenas y le dijo que llevase un trozo [de las cadenas] a su iglesia en Galicia. Y por el poder de esta cadena, los ladrones y todas las bestias salvajes huían ante él. Y así fue liberado».

32 Ibidem, vol. 1, p. 26. Proponemos la siguiente traducción al castellano para esta cita: "Aquí se cuenta de otro peregrino que fue encarcelado por error y Santiago rompió sus cadenas y le dijo que llevase un trozo de ellas a su iglesia».

33 Vid. Jean Froissart, Euvres de Froissart, vol. 17, p. 169.

34 Vid. ibidem, vol. 22, pp. 207-208. 
qu'il fut en Gascongne, et en ochit de sa main pluiseurs, les marechaulx de Mirepois et aultres» ${ }^{35}$.

Según una segunda redacción de este episodio, la peregrinación a Compostela por parte de Jean de Mauny fue un acto de reparación para con la familia del difunto y una medida destinada al mantenimiento de la paz: «Environ II ans ou III apriès, bonnes gens s'en ensonnyèrent, et en fu la pais faite, et en nom d'amende et de pais cils sires de Mauni en deubt aler, ensi qu' il fist, à Saint-Jakème de Galisse» ${ }^{36}$. Encontramos aquí un ejemplo de acuerdo privado entre las partes, gracias a la mediación de las bonnes gens mencionadas, que habrían actuado como arbitres. Sería una cierta forma de composición establecida entre las partes en conflicto, que se remonta a la justicia de raíz germánica ${ }^{37}$. Se evitaría así la venganza y con ella una posible sucesión de actuaciones violentas ${ }^{38}$. Con todo, y como se ha podido ver más arriba, Gauthier de Mauny no dejó impune la muerte de su padre ${ }^{39}$.

Es muy llamativa la coincidencia entre este relato de Jean Froissart y el final de Raoul de Cambrai, cantar de gesta del siglo XII. En esta obra, que relata los enfrentamientos entre la familia de Cambrai y la de Vermandois, Raoul (perteneciente a la primera) muere a manos de Bernier (miembro de la segunda) ${ }^{40}$. Posteriormente, hacia el final de la obra, Guerri, tío de Raoul, y Bernier, yerno del propio Berri, llegarán a reconciliarse ${ }^{41}$. Una forma de confirmación de la paz establecida entre ambas familias viene dada por el viaje que Guerri y Bernier hacen juntos a Santiago de Compostela, para rendir culto al apóstol:

Tant chevauchierent et par nuit et par dis,

$[\ldots]$

que a Saint Jaque vinrent a un mardi.

Au mostier vont quant ostel orent pris

le soir wellerent, chascun un sierge espris

au martinet vont le servise oïr ${ }^{42}$.

35 Ibidem, vol. 17, p. 169. Proponemos la siguiente traducción al castellano para esta cita: «Sin embargo, los parientes de este [del hermano de Jean de Lévis] mataron al caballero, y allí fue enterrado. Después el señor Gautier se tomó tan gran venganza que mató a todos los de Mirepoix, en el tiempo en que él estuvo luchando en Gascuña, y mató con sus propias manos a varios, a altos oficiales de Mirepoix y a otros».

36 Ibidem, vol. 4, p. 295. Proponemos la siguiente traducción al castellano para esta cita: «Unos dos o tres años después, gentes de bien se ocuparon [del asunto] y se hizo la paz, y a título de reparación y satisfacción, este señor de Mauny debió ir a Santiago de Galicia, y así lo hizo».

37 Vid. V. Toureille, Crime et châtiment, p. 163.

38 Vid. ibidem, p. 159.

39 Vid. también Jean Froissart, Euvres de Froissart, vol. 4, p. 294.

40 Vid. Anónimo, Raoul de Cambrai. Sarah Kay (ed.). Nueva York, Oxford University Press, 1992, p. 192, vv. 2968-2978.

41 Vid. ibidem, p. 480, vv. 8059-8075.

42 Ibidem, p. 486, vv. 8170-8175. Proponemos la siguiente traducción al castellano para esta cita: «Tanto cabalgaron noche y día. / [...] / que a Santiago llegaron un martes. / a la iglesia fue- 
Al terminar el viaje de regreso, Guerri y Bernier pasan por Origny y por el lugar donde Bernier dio muerte a Raoul. Al recordar Bernier tan triste episodio, Guerri es presa de la ira y golpea a aquel, hiriéndole de muerte:

Tout bellement son estrier despendi, parmi le chief B[erneçon] en feri, le tes li brise et $1[\mathrm{a}]$ char li ronpi, enmi la place la cervelle en chai ${ }^{43}$.

Así pues, el caso narrado por Jean Froissart y el desenlace de Raoul de Cambrai muestran un concepto feudal de la justicia y su continuidad a lo largo de la Edad Media hasta, al menos, el siglo xIv. Estos textos presentan dos soluciones ante el delito o el agravio: el acuerdo pacífico o la venganza y la guerra privada. En primer lugar, se pone en práctica la instauración de la paz. La peregrinación a Compostela sería la forma de confirmar la implantación de esta nueva situación. En segundo lugar, se acaba imponiendo la violencia como forma definitiva de zanjar desacuerdos y resentimientos entre las partes enfrentadas. La peregrinación no ha sido más que un paréntesis de paz, un falso desenlace positivo a conflictos señoriales cuyos protagonistas sólo serán capaces de resolver mediante las armas ${ }^{44}$.

Según señala Valérie Toureille, el género del cantar de gesta, al igual que los textos literarios en general, no aporta mucha información acerca del crimen en la Francia medieval: «La chanson de geste, qui constitue l'une des parts importantes de la production littéraire, projette un idéal de justice qui demeure sous le regard de Dieu. Si elle prétend fournir l'illustration d'une norme, cette norme nous échappe souvent» ${ }^{45}$. Sin embargo, Raoul de Cambrai sí proporciona una muestra interesante sobre la fuerza de la venganza privada en el universo feudal. El episodio contado por Jean Froissart viene a ser un refrendo a posteriori, por parte de la realidad histórica, de lo relatado en la ficción de Raoul de Cambrai. Su carácter tardío, en relación con esta última obra, es muestra de la mencionada pervivencia de este concepto de justicia hasta los últimos siglos de la Edad Media ${ }^{46}$.

El caso de Jean de Mauny nos lleva a abordar la peregrinación a Compostela como condena por la comisión de algún delito. Esta práctica, corriente en el

ron después de encontrar alojamiento, / por la noche hicieron vigilia, con un cirio en la mano; / al amanecer fueron a oír misa».

43 Ibidem, pp. 488-490, vv. 8230-8233. Proponemos la siguiente traducción al castellano para esta cita: «Muy despacio soltó su estribo, / hirió a Bernier en la cabeza, / la cabeza y la carne le rompió, / por el suelo cayeron sus sesos».

44 Vid. al respecto A. LABBÉ, «Sous le signe de saint Jacques: chemins et routes dans la représentation épique de l'espace», en Gabriel Bianciotto y Claudio Galderisi (dirs.), L'Epopée romane. 2 vols. Poitiers, Université de Poitiers, Centre d'études supérieures de civilisation médiévale, 2002, vol. 1, pp. 102-103 y 111 (en adelante A. LabBÉ, «Sous le signe de saint Jacques»).

45 V. Toureille, Crime et châtiment, p. 20.

46 Vid. ibidem, p. 172. 
ejercicio de la justicia eclesiástica en la Edad Media, se imponía tanto a miembros del clero como a seglares ${ }^{47}$.

La persecución de que fueron objeto los cátaros y otros herejes por la Inquisición incluyó el recurso a este castigo. Uno de los centros de culto importantes a los que se obligaba a acudir a las personas sentenciadas era precisamente Compostela $^{48}$. En este sentido, Bonifacio Palacios Martín hace notar que entre las distintas clases de viajeros que transitaban por los caminos de Santiago «hay que destacar a los herejes. En unos casos, se trataba de conversos que cumplían penitencias impuestas por la Inquisición pontificia u otros organismos ${ }^{49}$. Las autoridades inquisitoriales francesas ejercían un control burocrático riguroso, para asegurarse del cumplimiento real de la pena de peregrinación ${ }^{50}$.

La peregrinación pasará a aplicarse igualmente como condena en la justicia civil. Será en los Países Bajos donde primeramente se llevará a cabo tal iniciativa ${ }^{51}$. Esto es muestra de que durante la Edad Media la justicia eclesiástica y la civil no coexistieron en una situación de mutua ignorancia ${ }^{52}$. Philippe de Beaumanoir se hace eco igualmente en sus Coutumes de Beauvaisis de un caso que ilustra esta práctica judicial. Pero lo hace para señalar el carácter excesivo (ajeno a droit y a pitié) de la pena establecida ${ }^{53}$. Se determina que el condenado

iroit a Nostre Dame de Bouloigne nus piés et mouveroit l'endemain que li dis fu rendus; et, quant il seroit revenus en sa meson il n'i pourroit estre que .vIII. jours, et au nuevisme il mouveroit a aler a Saint Jaque en Galice et, quant il seroit revenus il mouveroit au nuevisme jour a pié a aler a Saint Gile en Provence; et, quant il seroit revenus, au quinzisme jour, il mouveroit a aler outre mer et i demourroit .III. ans, et raporteroit bonnes letres qu'il i avroit demouré .III. ans ${ }^{54}$.

47 Vid. L. Vázquez de Parga, J.M. a Lacarra y J. Uría Ríu, Las peregrinaciones, vol. 1, pp. 155-157 y E. VAN CAUWENBERGH, Les pèlerinages expiatoires et judiciaires dans le droit communal de la Belgique au Moyen Âge. Lovaina, Bureaux de Recueil, 1922, pp. 10-11 (en adelante E. VAN Cauwenbergh, Les pèlerinages expiatoires).

48 Vid. L. Vázquez de Parga, J.M. a Lacarra y J. Uría Ríu, Las peregrinaciones, vol. 1, p. 158 .

49 B. Palacios Martín, «La circulación de los cátaros por el Camino de Santiago y sus implicaciones socioculturales. Una fuente para su conocimiento». En la España medieval, vol. 3 (1982), p. 219.

50 Vid. B. Gui, Manuel de l'inquisiteur. G. Mollat (ed.). París, Les Belles Lettres, 2007, pp. LVI-LVII.

51 Vid. E. Van Caumenbergh, Les pèlerinages expiatoires, pp. 23-27 y L. Vázquez de Parga, J.M.a. Lacarra y J. URía Ríu, Las peregrinaciones, vol. 1, pp. 159-163.

52 Vid. E. Van Cauwenbergh, Les pèlerinages expiatoires, p. 23 y N. Gonthier Le châtiment du crime, p. 193.

53 Vid. N. Gonthier Le châtiment du crime, pp. 173-174.

54 Philippe de Beaumanoir, Coutumes de Beauvaisis, vol. 2, p. 168. Proponemos la siguiente traducción al castellano para esta cita: «Iría a Nuestra Señora de Boulogne con los pies descalzos y se marcharía al día siguiente de haber cumplido el castigo y, cuando hubiera vuelto a su casa, no podría permanecer allí más que ocho días, y al noveno se dispondría a ir a Santiago en Galicia y, cuando hubiera vuelto, se iría al noveno día a pie a Saint-Gilles en Provenza; y cuando hubiera 
El cronista y narrador Philippe de Vigneulles (1471-1528) también ofrece en sus Chroniques de la noble ville et cité de Metz informaciones interesantes sobre la peregrinación a Santiago de Compostela como penitencia. En 1480, con ocasión de la Anunciación de la Virgen, desde la víspera fue concedida por el papa una absolución general. Cualquier falta quedaba así perdonada en confesión. Sin embargo, la realización de las peregrinaciones a Roma, Santiago de Compostela y Jerusalén quedaban excluidas de este perdón:

La vigille de l'anunciation Nostre Dame, à vespre, entront de grans pardons generalz, donnez par nostre sainct pere le pape, de pleniere remission de peine et de coulpe, en la grande eglise [de Metz], comme l'an jubilé. [...] et quiconque contribuoit de ses biens [...] il avoit puissance d'eslire confesseur à son plaisir [...], lequel confesseur avoit pleine puissance [...] de donner pleine absolution et remission de peine et de coulpe et de tous cas quelconques, reservés les quatre veuls, assavoir, de Jerusalem, de Rome, de sainct Jacques et de religion ${ }^{55}$.

Asimismo, en 1495, durante la Semana Santa, se concedió otro perdón general a los fieles. Como en 1480, no afectaba al cumplimiento de las peregrinaciones mayores: Roma, Compostela y Jerusalén:

Le seiziesme jour d'apvril, le dix septiesme, le dix huictiesme, qui furent le grant jeudi, le grant vendredi, le grant samedi, y eult en la grant eglise de Mets pardons generalz de pleine remission de tous pechiés, reservé le veu de Rome, de sainct Jaicque, de Jherusalem, de chasteté et de continence. Lesquelz pardons estoient à cause d'une graice venue des grans pardons de la maison Dieu à Paris ${ }^{56}$.

Puesto que se trata, en las dos situaciones relatadas por Philippe de Vigneulles, de una absolución general de pecados, cabe pensar que este autor hace alusión a las tres grandes peregrinaciones como castigos o penitencias impuestos por la Iglesia. La importancia y magnitud de los trayectos a estos centros de culto lleva también a creer que quienes son condenados a acudir a ellos han sido responsables de

vuelto, al décimo quinto día se iría a ultramar [Tierra Santa] y permanecería allí tres años, y traería cartas [que demostrasen] que había estado allí tres años».

$55 \mathrm{Ph}$. De Vigneulles (et al.), Les Chroniques de la ville de Metz. S. Lamort (ed.). Metz, S. Lamort, 1838, pp. 433-434. Proponemos la siguiente traducción al castellano para esta cita: «La vigilia de la Anunciación, en la víspera, comenzaron las grandes indulgencias generales, concedidas por nuestro Santo Padre el Papa, con plena remisión de pena y de culpa, en la catedral [de Metz], como en ańo jubilar. [...] y todo aquel que contribuyera con sus bienes [...] podría elegir confesor a su gusto [...] y este confesor tendría plena potestad [...] para dar plena absolución y remisión de pena y de culpa en todos los casos, con excepción de los cuatro votos, a saber, los de Jerusalén, Roma, Santiago y los votos religiosos».

56 Ibidem, p. 605. Proponemos la siguiente traducción al castellano para esta cita: «Los días dieciséis, diecisiete y dieciocho de abril, que fueron Jueves Santo, Viernes Santo y Sábado Santo, hubo en la catedral de Metz indulgencias generales, con plena remisión de todos los pecados; se exceptúan los votos de Roma, Santiago y Jerusalén, los de castidad y de abstinencia. Estas indulgencias se concedieron por una gracia procedente del hospicio de París». 
pecados de mucha gravedad y que no pueden por ello acogerse a dicha indulgencia. Por otra parte, no hay que olvidar que, como señala Nicole Gonthier ${ }^{57}$, la condena de peregrinación podía utilizarse como una medida de gracia que evitaba al culpable una pena de prisión prolongada. Por lo tanto, no parecería muy correcto concederle dos medidas de indulgencia.

El género del fabliau ofrece un ejemplo en el que se menciona la peregrinación como una dura condena que ocasiona gran sufrimiento físico. Se trata de la creación titulada De la dame qui fist batre son mari. En ella se muestra al personaje del marido celoso recibiendo tan gran paliza, a manos de un grupo de hombres que cumple órdenes de su esposa. Bien querría el desdichado estar peregrinando a Compostela o a Tierra Santa, antes que recibir semejante castigo: "A ceste ore volsist il bien / A Saint Jasque ou otremer estre ${ }^{58}$. Podría establecerse aquí una equiparación entre el escarmiento del marido y las peregrinaciones a los santuarios de Galicia o de Palestina, como condenas impuestas a los culpables de alguna fechoría.

En la Edad Media se permitía delegar en otra persona la realización de la peregrinación. No era una práctica extraña, pues «hubo peregrinos a sueldo y peregrinos por manda testamentaria" 59 . Como ya se ha dicho, el Dit des.III. pommes de Jean de Saint-Quentin narra en su primera parte una peregrinación hecha por un joven francés en lugar de su padre, muy viejo y enfermo como para cumplir el voto realizado en el pasado ${ }^{60}$. Dentro del campo judicial, en el territorio de la actual Bélgica era también corriente en la Edad Media la substitución en el cumplimiento de una peregrinación como condena impuesta por la justicia civil ${ }^{61}$.

El recurso a la pena de muerte como condena por crímenes y delitos no era demasiado habitual en la Francia de la Edad Media. La concepción religiosa de la justicia practicada por la Iglesia buscaba para el culpable la expiación, el arrepentimiento y la rectificación de su conducta ${ }^{62}$. Por ello, y como señala Valérie Toureille, «le Moyen Âge, pétri de morale religieuse, pratique la peine de mort avec parcimonie» ${ }^{63}$. A este respecto, cabe mencionar el Voiatge a St Jacques en Compostelle et a Nostre Dame de Finibus terre. Es un relato escrito por el noble gascón Nompar de Caumont que cuenta la peregrinación que él mismo hizo a Compostela en 1417. En él se incluye la narración de un milagro del apóstol Santiago. Tres peregrinos de Compostela (padre, madre e hijo) hicieron una parada en un albergue de Santo Domingo de la Calzada (La Rioja). Una criada, despechada por el rechazo

57 Vid. N. Gonthier Le châtiment du crime, pp. 118-119.

58 Anónimo, Recueil général et complet des fabliaux des XIII et XIVe siècles. 6 vols. Anatole de Montaiglon y Gaston Raynaud (eds.). París, Librairie des bibliophiles, 1872-1890, vol. 4, p. 140, vv. 251-252. Proponemos la siguiente traducción al castellano para esta cita: «En aquel momento bien hubiera querido / Estar en Santiago o en ultramar [Tierra Santa]».

59 L. Vázquez de Parga, J.M. a Lacarra y J. Uría Ríu, Las peregrinaciones, vol. 1, p. 155.

60 Vid. Jehan de Saint-Quentin, Dits, pp. 26-27.

61 Vid. E. Van Cauwenbergh, Les pèlerinages expiatoires, pp. 173-176.

62 Vid. V. Toureille, Crime et châtiment, p. 187.

63 Ibidem, p. 253. 
del hijo a sus requerimientos amorosos, introducirá en su escarcela una copa de plata y acusará de su robo a los peregrinos. Estos serán detenidos y el joven será condenado a la horca: «Et puis vont serchier l'enfant et trouvarent le tace en l'eschirpe où le servente l'avoit mise. De quoy les pélerins furent moult esbays; et alérent tourner l'enfant en le ville et là menèrent à le justice. Et fut jutgié estre pendu» ${ }^{64}$. Los padres, tras haber ido a Santiago, vuelven a pasar por la mencionada localidad y encuentran vivo a su hijo en la horca. Van ante el juez a contarle lo sucedido, y tiene lugar entonces el prodigio del gallo y la gallina, que cantan después de haber sido asados. Finalmente, la criada merecerá el mismo castigo que el joven inocente: «Et ycelle fust prise et comffessa le vérité, qu'elle l'avoit fait pour ce qu'il n'avoit voulu fere sa voulenté; et fut pendue» ${ }^{65}$.

Vemos, pues, que en este breve relato tienen lugar dos condenas capitales: la injusta y la merecida. Se puede decir que hay en él demasiada presencia de la muerte. Bien es cierto que el robo en la Francia de la Edad Media era un delito considerado como de una enorme gravedad, constituía todo un atentado contra la economía, contra la propiedad del individuo y contra la confianza entre las personas: «Il [el robo] devenait particulièrement odieux lorsqu'il était commis par un proche de la victime. La domestique qui volait son maitre [...] était lourdement punie, au titre d'une circonstance aggravante: la rupture de la confiance donnée» ${ }^{66}$. Podía incluso llegar a ser castigado con la muerte: "L'appréhension du "larrecin" médiéval, qui comprend toutes les formes de vol, y compris les plus graves, est de nature ambivalente. Il est le crime majeur, celui qui remet en cause l'ordre social. Mais dans le même temps, il recouvre souvent de bien modestes gestes et son traitement demeure aléatoire, allant de l'amende à la mort» ${ }^{67}$. De todas maneras, y al hilo de lo señalado anteriormente por Valérie Toureille acerca de la relativa poca frecuencia de la aplicación real de la pena de muerte en Francia en la Edad Media, parece claro que el recurso a la misma en este milagro se justifica por su carácter moralizador y de exaltación de la figura del apóstol Santiago. Este interviene, al igual que en los dos ejemplos tomados de $\mathrm{C} i$ nous dit, para rectificar un error judicial y para ayudar a castigar a quien de verdad ha obrado mal.

Además, hay en este relato un tipo de delito de indudable gravedad y de gran trascendencia en su desarrollo, pues llevará a su autora a la muerte, la falsa acusación:

64 Seigneur de Caumont, Voiatge à St Jaques de Compostelle et à Nostre Dame de Finibus Terre, en Voyaige d'Oultremer en Jhérusalem. Marquis de La Grange (ed.). París, Auguste Aubry, 1858, p. 144 (en adelante Seigneur de Caumont, Voiatge à St Jaques de Compostelle). Proponemos la siguiente traducción al castellano para esta cita: «Y después fueron a buscar al nińo y encontraron la taza en el morral donde la sirvienta la había metido. De lo cual quedaron muy asombrados los peregrinos. Hicieron volver al niño a la ciudad y le llevaron ante la justicia. Y fue condenado a la horca».

65 Ibidem, p. 145. Proponemos la siguiente traducción al castellano para esta cita: «Y esta [la criada] fue detenida y confesó la verdad, que ella lo había hecho porque él [el joven peregrino] no había querido satisfacer su deseo; y fue ahorcada».

66 V. Toureille, Crime et châtiment, p. 62.

67 Ibidem, p. 56. 
Et le nuyt, quant dormoit, elle entra en sa chambre et mist une tasse d'argent de celles de l'ouste en son échirpe. Et lendemain matin quant le père et mère et filz se levérent, tindrent leur chemin avant, et quant furent passés le ville, le servente dist asson mestre que une tasse estoit perdue et que lez pélerins qui léans avoient couchié, la devoient avoir emblé68.

La falsa acusación era una forma de actuación delictiva muy mal vista por la justicia francesa en la Edad Media: «Si les autorités supportent mal les injures, elles entendent pénaliser également les mensonges, surtout ceux qui égarent la justice et dénotent un mépris pour son sérieux» ${ }^{69}$. El Dit des. III. pommes refleja claramente este rechazo de la calumnia. Cuando el acompañante del muchacho que va a Compostela no encuentra a este, tras haber comprobado que nadie se ha ido de la población en la que han pasado la noche, acude a presencia del juez para denunciar su asesinato. Tanto él como el propio juez son plenamente conscientes de que es muy importante decir la verdad y no levantar falso testimonio contra nadie. Las consecuencias de tal delito pueden ser muy graves para quien lo cometa:

Amis, dit li prevos, gardes que tu diras,

Car se tu ne dis voir, en tel estat seras

Comme celui doit estre qui fait le maimes cas».

- «Sire, dit le preudom, je ne vous desdi $\operatorname{pas}^{70}$.

El Dit des Annelés es otro de los relatos piadosos debidos a Jehan de SaintQuentin. Es una creación especialmente interesante para los fines del presente trabajo, ya que en ella aparecen, junto con la pena de muerte, otros castigos y soluciones judiciales. Muestra en su primera parte una innegable semejanza con La Fille $d u$ Comte de Ponthieu. Un joven matrimonio sufre un grave percance en el transcurso de su peregrinación a Santiago de Compostela. También se comete, o está a punto de cometerse, una fechoría que afectará profundamente a la relación de la pareja. Sin embargo, aquí no se produce un asalto violento, con robo y violación, por parte de unos bandoleros. Lo que tiene lugar es un engaño al marido, con un intento frustrado de adulterio por parte de la esposa y un caballero, compańero de viaje encontrado en la ruta hacia Galicia. Este se había hecho inicialmente amigo

68 Seigneur de Caumont, Voiatge à St Jaques de Compostelle, p. 144. Proponemos la siguiente traducción al castellano para esta cita: «Y por la noche, mientras [el joven peregrino] dormía, [la criada] entró en su habitación y puso una de las tazas de plata del posadero en su morral. A la mańana siguiente, cuando el padre, la madre y el hijo se levantaron, prosiguieron su camino, y cuando habían dejado atrás la ciudad, la criada dijo a su amo que faltaba una taza y que los peregrinos que habían pasado la noche allí debían haberla robado».

69 N. Gonthier, Le châtiment du crime, p. 141.

70 Jehan de Saint-Quentin, Dits, p. 32, vv. 181-184. Proponemos la siguiente traducción al castellano para esta cita: "Amigo", dijo el juez, "ten cuidado con lo que dices, / Porque si no dices la verdad, acabarás / Como merece todo aquel que me miente." / "Señor", dijo el buen hombre, "no os contradigo"». 
de los dos peregrinos, pero luego demostrará que no es más que un felón. Así lo anuncia el narrador:

Mes ou chemin trouverent un autre chevalier.

De leur païs estoit, n'out qu'un garçon trotant;

O ceus s'acompaigna dont je vous voiz parlant.

Au premier leur moustra d'amistié grant samblant;

Mais puis les tourmenta, com vous orréz avant ${ }^{71}$.

Nos encontramos aquí con una falta muy grave como es la traición, tanto por parte de la esposa como del caballero. Atenta contra unos valores a los que en la Edad Media se les da una gran importancia: el honor, la palabra dada, el respeto a las jerarquías:

Trahison-loyauté, franchise-dissimulation, c'est à partir de ces contraires que se sont forgées les valeurs les plus essentielles de la société médiévale. [...] Dans tous les cas, la trahison est perçue comme inacceptable, parce qu'elle remet en cause l'ordre du monde et sa hiérarchie naturelle. Le traître, par conséquent, est dépeint sous les couleurs les plus noires, pour mieux exorciser le danger qu'il représente ${ }^{72}$.

El adulterio, falta de incuestionable gravedad a pesar de no haber sido consumado, se ve agravada por la desleal reacción de la esposa sorprendida, que reniega de su marido:

La dame, qui estoit ou lit trestoute nue,

Pour honte de la gent fu si fort esperdue

Qu'a son mari a dit com fole malostrue

Que rien ne li estoit; trop fort fu deceüe ${ }^{73}$.

A su regreso, el marido engañado expone su caso como si le hubiera ocurrido a un amigo suyo. Lo hace públicamente, durante un banquete al que asisten los amigos de su esposa y el padre de esta. Tras haber contado el suceso, pide a los presentes su opinión sobre el castigo que merece la esposa adúltera. Es el padre de ella quien da respuesta a tal petición:

71 Ibidem, p. 192, vv. 116-120. Proponemos la siguiente traducción al castellano para esta cita: «En el camino se encontraron con otro caballero / Que era de su país; solamente le acompañaba un criado; / Se unió a estos de quienes os estoy hablando. / Al principio se mostraba muy amable con ellos; / Pero después les causó gran sufrimiento, como oiréis más adelante».

72 V. Toureille, Crime et châtiment, p. 88.

73 Jehan de Saint-Quentin, Dits, p. 196, vv. 213-216. Proponemos la siguiente traducción al castellano para esta cita: «La dama, que estaba en la cama completamente desnuda, / Se sintió tan abrumada por la vergüenza pública / Que como una loca desdichada dijo a su marido / Que nada tenía que ver con él; muy gravemente mintió». 
Lors le pere a la dame, qui estoit touz flouris,

Qui ne sout pas pour quoy tiex moz estoient dis,

Respondi: «Voir, s'estoie de tel fame garnis

Qui m'aroi fet tel honte, son corps seroit bruïs».

A son dit s'acorda la compaignie toute ${ }^{74}$.

Esta intervención refleja dos aspectos importantes de la impartición de justicia a las mujeres en la Edad Media. Uno es la práctica habitual (pero no única) de condenar a las culpables de un delito a morir en la hoguera ${ }^{75}$ : "Les juges manifestent une prédilection pour l'eau [ahogamiento] et le feu quand il s'agit d'éliminer physiquement des criminelles» ${ }^{76}$. El otro aspecto es la autoridad que se le reconoce en la Edad Media al padre para castigar a su hija adúltera, incluso con la muerte: «Le droit romain permettait au père de la femme adultère de la tuer, et son complice avec elle s'il les prenait en flagrant délit. Le droit coutumier médiéval admet très généralement l'impunité du père et du mari ou même celle du frère de la femme adultère»77.

Además de la traición por intentar seducir a la mujer, el caballero felón comete otras dos malas acciones. En primer lugar, no duda en mentir, cuando dice que él es el esposo de la mujer. En segundo lugar, lanza un desafío al auténtico marido a librar con él un combate singular que habrá de servir para solucionar la situación de conflicto que él mismo ha creado.

«Mes il ne dit pas voir, Diex en scet mon courage.

Il n'a rien en la dame: je l'ay par mariage;

Et se desdidre l'ose, contre li tent mon gage».

Lors le mari la dame, qui estoit preuz et sage,

D'aïr bailla son gant, au baillif l'a tendus,

Puis a dit en tel guyse: «Se ne l'en rent confus,

Je m'acort que je soie com recreant pendus;

Et se il avient chose que par moy soit vaincus,

Qu'a mon talent me puisse de ma fame vengier

Et la puisse mener en mon païs arrier,

Et li glouz soit pendus, qui m’a voulu trichier».

Lors l'autre dist en hault: «Bien m’y vueil otroier» ${ }^{78}$.

74 Ibidem, p. 204, vv. 441-445. Proponemos la siguiente traducción al castellano para esta cita: «Entonces el padre, que tenía la barba blanca, / Y que no sabía por qué tales palabras habían sido dichas, / Respondió: "Verdaderamente, si yo tuviera una mujer / Que me hubiera hecho semejante ofensa, haría quemar su cuerpo". / Toda la concurrencia estuvo de acuerdo con lo que dijo».

75 Vid. V. Toureille, Crime et châtiment, pp. 256-257.

76 N. Gonthier Le châtiment du crime, p. 161.

77 V. Toureille, Crime et châtiment, p. 294.

78 Jehan de Saint-Quentin, Dits, p. 196, vv. 225-236. Proponemos la siguiente traducción al castellano para esta cita: “"Él no dice la verdad, Dios sabe lo que siento. / Él no tiene nada que ver con la dama: yo la tengo por matrimonio; Y si osa contradecirlo, contra él lanzo mi guante”. / Entonces el marido de la dama, que era valiente y sabio, / Con ira cogió su guante y lo entregó al juez, / Después dijo así: "si no lo mato [al caballero], / Aceptaré, como vencido, ser ahorcado; / Y si 
Se plantea así un duelo judicial. El criterio en el que se basa esta forma de resolución de conflictos es que el vencedor ha contado con el apoyo de Dios. Se entiende que Dios lo considera inocente de la acusación o asistido por la razón:

Quand deux plaignants s'opposaient, on les mettait parfois en situation de prouver leur bonne foi par les armes. Ainsi se déroulait le duel judiciaire ou «la bataille», issus de la primitive ordalie, qui reposaient sur un principe ne souffrant aucune contestation: c'était toujours Dieu qui guidait le bras du vainqueur ${ }^{79}$.

En el combate entre el caballero traidor y el marido de la mujer infiel será este quien venza. No sólo cuenta con el auxilio de Dios, pues el apóstol Santiago, al que profesa una gran devoción, también está de su parte. El caballero derrotado deberá reconocer su mal proceder y por ello sufrirá su merecido castigo, ya acordado: la muerte por ahorcamiento.

Quant cil senti le coup, lors dist a haute voiz:

«Sire, pour Dieu merci, ma mauvestié congnois:

Vostre fame requis d'amer par pluseurs foiz;

De male eure la vi: pour li a ma fin voiz.

$[\ldots] »$

Lors quant les nobles hommes la traïson oïrent,

Traïner au gibet et puis pendre le firent ${ }^{80}$.

La horca es una forma de ejecución considerada en la Edad Media como muy denigrante para una persona de elevada posición social. El texto deja así constancia de la maldad del caballero y del final que merece: «La peine de mort est une peine distinctive. L'origine du condamné induit le mode d'exécution. Le vilain est pendu quand le noble est décapité. Les quelques exceptions à cette règle intangible ne sont là que pour la confirmer, comme une modalité aggravée de la dégradation ${ }^{81}$.

El castigo para la esposa no será la muerte sino el destierro, impuesto por su marido. Es una alternativa a la ejecución:

Lors parla son mari, qui estoit preuz et sage,

Et dist: «Seigneurs, ma fame est de vostre lignage;

Sachiéz bien que c'est celle qui m’a fet tel domage;

sucede que él sea derrotado por mí, / Podré vengarme de mi mujer como yo quiera / Y la podré llevar de nuevo a mi país. / Y que el canalla que ha querido engañarme sea ahorcado". / Entonces dijo el otro: "Estoy de acuerdo"».

79 V. Toureille, Crime et châtiment, p. 85.

80 Jehan de Saint-Quentin, Dits, pp. 200-201, vv. 345-355. Proponemos la siguiente traducción al castellano para esta cita: «Cuando este [el caballero] sintió el golpe, dijo en voz alta: / "Señor, por la gracia de Dios, reconozco mi mal proceder: / A vuestra mujer intenté seducir varias veces; / En mala hora la vi: por ella voy a mi final. / [...]" / Cuando los nobles hombres oyeron la traición, / Lo llevaron a la horca y después lo hicieron colgar».

81 V. Toureille, Crime et châtiment, p. 255. 
Mes ne sera pas arse, car je n'en ay courage,

Et s'en penrai venjance crueuz par autre tour» 82 .

La ficción muestra aquí un hecho propio de la realidad judicial en la Francia medieval: «Autre peine d'exclusion, substitut à la peine de mort sans en avoir les conséquences, le bannissement était le châtiment le plus utilisé dans les villes, où il apparaissait comme le moyen le plus commode de se débarrasser d'individus trop encombrants» ${ }^{83}$. Semejante condena suponía para quien la sufría un absoluto descrédito:

La peine sanctionne profondément celui auquel elle s'applique. [...] La sentence ne l'arrache pas seulement à sa famille et à sa patrie, l'assimilant à un errant qui suscite partout soupçons et crainte, elle l'exclut de toute forme de sociabilité. La condition qu'on lui impose équivaut à un blâme permanent ${ }^{84}$.

El destierro iba precedido de otras medidas que acentuaban su carácter ultrajante. Se realizaba un trayecto que debía avergonzar a la persona condenada: "La plupart du temps, le bannissement était précédé du "chemin de la honte", un rite processionnel qui conduisait le condamné à la limite du ressort, assorti d'une grande variété de gestes infamants ou dégradants» ${ }^{85}$. Además, se podía aplicar al condenado alguna marca o castigo corporal ${ }^{86}$. Puede decirse que la esposa infiel sufre tanto el camino hacia la expulsión como la imposición de marcas. Será llevada al puerto de Ouessant, donde se le pondrán diez anillos de acero, uno en cada dedo: "Qu'ennelés ot fet fere, gros et rudes de fer; / Es .X. dois a la dame les a fet .X. bouter / Si fort qu'il n'estoit homme qui les poïst oster ${ }^{87}$. A continuación, la dama es desterrada, pues se la deja sola en un barco, a merced de las olas: «En un batel la mist ou il n'avoit riens nee, / Puis la bouta en mer de moult grant alenee» ${ }^{88}$.

82 Jehan de Saint-Quentin, Dits, p. 204, vv. 449-453. Proponemos la siguiente traducción al castellano para esta cita: «Entonces habló su marido, que era valiente y sabio, / Y dijo: "Señores, mi mujer es de vuestro linaje; / Sabed bien que es ella quien me ha causado tanto dańo; / Pero no será quemada, porque no es mi intención, / Tomaré venganza por otro medio"».

83 V. Toureille, Crime et châtiment, p. 258.

84 N. Gonthier Le châtiment du crime, 140.

85 V. Toureille, Crime et châtiment, p. 259.

86 Vid. N. Gonthier Le châtiment du crime, 140.

87 Jehan de Saint-Quentin, Dits, p. 205, vv. 469-471. Proponemos la siguiente traducción al castellano para esta cita: «Mandó hacer unos anillos de hierro, gruesos y toscos, / En sus diez dedos mandó poner a la dama diez [anillos] /Tan fuertemente que no había hombre que se los pudiera quitar».

88 Ibidem, vv. 477-478. Proponemos la siguiente traducción al castellano para esta cita: «La metió en un barco en el que no había nada, / Después la lanzó al mar con un fuerte impulso del viento». 


\section{CONCLUSIÓN}

La peregrinación a Compostela no es un tema mayor de la literatura francesa. Ciertamente, su existencia es más notable en las creaciones medievales, ya que la Edad Media fue la época de mayor esplendor del culto jacobeo. Pero incluso en estos textos, tal presencia no es demasiado profunda. El cantar de gesta es el género literario medieval que más atención le ha prestado. El Camino de Santiago es un aspecto destacable de la España que se recoge en los textos épicos franceses. A pesar de ello, no llega a ser un elemento de contenido capital de estas obras. Jean Subrenat, señala al respecto:

La route de saint Jacques n'a intéressé les chanteurs de geste que dans la mesure où elle était l'objet d'exploits militaires et de reconquête contre les musulmans [...]. Bref, le chemin de Compostelle n'est pas un grand axe épique et l'apôtre de Galice est sans doute trop spiritualisé ou cléricalisé pour intervenir trop directement aux côtés des chevaliers ${ }^{89}$.

La mayor parte de las producciones estudiadas para el presente trabajo son también una muestra de esta circunstancia. La ruta jacobea vinculada con el mundo delictivo y judicial tiene en ellas un peso secundario. No es el caso, obviamente, del relato de Nompar de Caumont ni del milagro de gallo y la gallina incluido en él.

Sin embargo, sí podemos decir que el mundo jacobeo tiene una presencia extensa en la literatura francesa medieval, tanto en un sentido cronológico como genérico. El culto al apóstol Santiago aparece en obras repartidas entre los siglos XII y Xv. Durante este período tan largo, y hasta el surgimiento del protestantismo, se acude a Compostela de manera continuada, lo cual sustenta la producción constante de obras que le dan cabida. Como se ha podido ver aquí, ciñéndonos al tema concreto y más específico que nos ocupa, aparece en creaciones pertenecientes a una variedad de géneros que no es desdeñable. Asimismo, la diversidad y complejidad del conjunto de aspectos legales jacobeos recogidos en las distintas obras estudiadas es destacable: la protección legal del peregrino; delitos como el robo, las falsas acusaciones, la violación; la impunidad; diversas clases de condenas, castigos y penitencias: la misma peregrinación a Compostela, el destierro, los paseos de la vergüenza y las marcas infamantes, la pena de muerte; la composición entre iguales y el duelo judicial.

Esta circunstancia, curiosa y paradójica, podría explicarse, a nuestro entender, por el hecho de que desde Francia Compostela era visto probablemente como un centro de culto de incuestionable importancia, pero muy lejano. Además, en lo que concierne al norte de Francia, y tomando como referencia literaria el género del cantar de gesta, Compostela empezó a adquirir notoriedad a partir de finales del

89 Subrenat, Jean, «Saint Jacques, ses pèlerins, son chemin dans les chansons de geste françaises», en VIII Congreso de la Société Rencesvalls. Pamplona, Institución Príncipe de Viana, 1981, p. 510. 
siglo $\mathrm{XII}^{90}$. Es esta lejanía y esta difusión tardía de su fama lo que haría que el santuario gallego de Santiago no fuera sentido más allá de los Pirineos como un patrimonio espiritual propio y arraigado, sino como un lugar prestigioso pero también extranjero. El renombre de Compostela justificaría la abundancia de alusiones que se hacen al universo jacobeo en los textos literarios franceses de la Edad Media, entre las cuales se incluyen las relativas a delincuencia y justicia. Su condición de centro de culto ajeno explicaría la superficialidad y el carácter secundario de dichas alusiones. Una prueba de esto, dentro de los límites del presente trabajo, podría ser la escasez de datos concretos acerca de las rutas jacobeas en las obras analizadas. Así, por ejemplo, La Fille du comte de Ponthieu, el Dit des.III. pommes y el Dit des Annelés, obras cuyos protagonistas aparecen inicialmente como peregrinos de Santiago, carecen de precisiones geográficas al respecto. Asimismo, en Raoul de Cambrai, la narración del viaje a Compostela realizado por Bernier y Guerri incluye algunas de las primeras etapas en territorio francés: la region de Berry, Poitiers, Blaye, Burdeos y las Landas ${ }^{91}$. Pero no se menciona ni una sola localidad situada en Espańa ${ }^{92}$.

El rasgo distintivo del universo jacobeo como tema de la literatura francesa medieval es esta contradicción entre la superficialidad y la continuidad de su presencia. Es un contenido secundario, pero nunca ausente a lo largo de los siglos. La delincuencia y la justicia son dos elementos que se integran en él. En consecuencia, participan de dicho rasgo, que le confiere indudable interés como objeto de estudio.

ReCiBIDO: 29-10-2018; ACEPTADo: 30-5-2019

90 Vid. P.-G. Girault, «Compostelle dans les chansons de geste françaises, une approche chronologique», en Adeline Rucquor (ed.), Saint Jacques et la France, París, Les Éditions du Cerf, 2003, p. 347.

91 Vid. Anónimo, Raoul de Cambrai, p. 486, vv. 8163-8168.

92 Vid. supra la cita con los versos 8170-8175 de Raoul de Cambrai. En esta cita falta el verso 8171: «Par le bel tant et par le lait ausis» (traducción al castellano: «Con tiempo bueno y malo»). Vid. también A. LABBÉ, «Sous le signe de saint Jacques», p. 104. 


\section{BIBLIOGRAFÍA}

Anónimo, Ci nous dit. Recueil d'exemples moraux. 2 vols. Gérard Bangez (ed.). París, Société des Anciens Textes Français, 1979-1986.

Anónimo, La hija del conde de Ponthieu / La fille du Comte de Ponthieu. Esperanza Cobos Castro (ed.). Barcelona, Bosch, 1988.

Anónimo, Raoul de Cambrai. Sarah Kay (ed.). Nueva York, Oxford University Press, 1992.

AnónImo, Recueil général et complet des fabliaux des XIII et XIVe siècles. 6 vols. Anatole de Montaiglon y Gaston Raynaud (eds.). París, Librairie des bibliophiles, 1872-1890.

Bernard Gui, Manuel de l'inquisiteur. G. Mollat (ed.). París, Les Belles Lettres, 2007.

Eustache Deschamps, Euvres complètes d'Eustache Deschamps. 11 vols. Marqués de Queux de Saint-Hilaire y Gaston Raynaud (eds.). París, Firmin Didot, 1878-1903.

Girault, Pierre-Gilles, "Compostelle dans les chansons de geste françaises, une approche chronologique», en Adeline Rucquor (ed.), Saint Jacques et la France, París, Les Éditions du Cerf, 2003, pp. 331-347.

Gonthier, Nicole, Le châtiment du crime au Moyen Âge: XII ${ }^{e}-X V I^{e}$ siècles. Rennes, Presses Universitaires de Rennes, 1998.

Jean Froissart, Euvres de Froissart. Chroniques. 25 vols. Barón Kervyn de Lettenhove (ed.). Bruselas, Devaux, 1867-1877.

Jehan de Saint-Quentin, Dits en quatrains d'alexandrins monorimes de Jehan de Saint-Quentin. Birger Munk Olsen (ed.). París, Société des Anciens Textes Français, 1978.

LABBÉ, Alain, «Sous le signe de saint Jacques: chemins et routes dans la représentation épique de l'espace», en Gabriel Bianciotto y Claudio Galderisi (eds.), L’Epopée romane. 2 vols. Poitiers, Université de Poitiers, Centre d'études supérieures de civilisation médiévale, 2002, vol. 1, pp. 99-116.

Lejeune, Rita, «Une nouvelle française du XIII ${ }^{e}$ siècle et un film japonais de 1951», en Studi in onore di Italo Siciliano. 2 vols. Florencia, Leo S. Olschki, 1966, vol. 2, pp. 637-649.

Palacios Martín, Bonifacio, «La circulación de los cátaros por el Camino de Santiago y sus implicaciones socioculturales. Una fuente para su conocimiento». En la España medieval, vol. 3 (1982), pp. 219-229.

Philippe de Beaumanoir, Coutumes de Beauvaisis. 2 vols. A. Salmon (ed.). París, Picard, 1899-1900.

Seigneur de Caumont Voiatge à $S^{t}$ Jaques de Compostelle et à Nostre Dame de Finibus Terre, en Voyaige d'Oultremer en Jhérusalem. Marquis de La Grange (ed.). París, Auguste Aubry, 1858, pp. 141-150.

Subrenat, Jean, «Saint Jacques, ses pèlerins, son chemin dans les chansons de geste françaises», en VIII Congreso de la Société Rencesvalls. Pamplona, Institución Príncipe de Viana, 1981, pp. 505-510.

Toureille, Valérie, Crime et châtiment au Moyen Âge: ve-Xve siècle. París, Seuil, 2013.

Van Caumenbergh, Étienne, Les pèlerinages expiatoires et judiciaires dans le droit communal de la Belgique au Moyen Âge. Lovaina, Bureaux de Recueil, 1922.

VÁzquez de Parga, Luis, Lacarra, José M. a y Uría Ríu, Juan, Las peregrinaciones a Santiago de Compostela. 3 vols. Madrid, Consejo Superior de Investigaciones Científicas, 1949.

Vigneulles, Philippe de (et al.), Les Chroniques de la ville de Metz. S. Lamort (ed.). Metz, S. Lamort, 1838. 